\title{
Protoplast transformation as a potential platform for exploring gene function in Verticillium dahliae
}

\author{
Latifur Rehman ${ }^{\dagger}, X_{i a o f e n g ~ S u^{\dagger}}$, Huiming Guo, Xiliang Qi and Hongmei Cheng ${ }^{*}$
}

\begin{abstract}
Background: Large efforts have focused on screening for genes involved in the virulence and pathogenicity of Verticillium dahliae, a destructive fungal pathogen of numerous plant species that is difficult to control once the plant is infected. Although Agrobacterium tumefaciens-mediated transformation (ATMT) has been widely used for gene screening, a quick and easy method has been needed to facilitate transformation.

Results: High-quality protoplasts, with excellent regeneration efficiency (65 \%) in TB3 broth (yeast extract $30 \mathrm{~g}$, casamino acids $30 \mathrm{~g}$ and $200 \mathrm{~g}$ sucrose in $1 \mathrm{~L} \mathrm{H}_{2} 0$ ), were generated using driselase (Sigma D-9515) and transformed with the GFP plasmid or linear GFP cassette using PEG or electroporation. PEG-mediated transformation yielded 600 transformants per microgram DNA for the linear GFP cassette and 250 for the GFP plasmid; electroporation resulted in 29 transformants per microgram DNA for the linear GFP cassette and 24 for the GFP plasmid. To determine whether short interfering RNAs (siRNAs) can be delivered to the protoplasts and used for silencing genes, we targeted the GFP gene of Vd-GFP ( $V$. dahliae GFP strain obtained in this study) by delivering one of four different siRNAs-19-nt duplex with 2-nt 3' overhangs (siRNA-gfp1, siRNA-gfp2, siRNA-gfp3 and siRNA-gfp4) -into the Vd-GFP protoplasts using PEG-mediated transformation. Up to $100 \%$ silencing of GFP was obtained with siRNA-gfp4; the other siRNAs were less effective (up to $10 \%$ silencing). Verticillium transcription activator of adhesion ( $V t a 2)$ gene of $V$. dahliae was also silenced with four siRNAs (siRNA-vta1, siRNA-vta2, siRNA-vta3 and siRNA-vta4) independently and together using the same approach; siRNA-vta1 had the highest silencing efficiency as assessed by colony diameter and quantitative real time PCR (qRT-PCR) analysis.
\end{abstract}

Conclusion: Our quick, easy transformation method can be used to investigate the function of genes involved in growth, virulence and pathogenicity of $V$. dahliae.

Keywords: Verticillium dahliae, Driselase, Transformation, siRNAs

\section{Background}

$V$. dahliae, the causal agent of Verticillium wilt, is one of the most destructive plant pathogens, affecting over 400 plant species, including important ornamental, horticultural, agronomical and woody plants $[1,2]$. Its control is difficult because it produces microsclerotia, which can survive in soil for several years [3]. Moreover, no effective fungicides or other chemicals are available to overcome this pathogen once the plant is infected.

\footnotetext{
*Correspondence: chenghongmei@caas.cn

${ }^{\dagger}$ Equal contributors

Biotechnology Research Institute, Chinese Academy of Agricultural Sciences, Beijing 100081, China
}

Despite a great deal of research, the molecular mechanisms behind the pathogenicity of this fungus have remained unclear [1].

An efficient transformation system is necessary for genetic manipulation and functional genomics studies of fungi [4]. A number of methods, Agrobacterium tumefaciens-mediated transformation (ATMT), PEG-mediated transformation, electroporation, and particle bombardment, have been used to transform different fungal species, including $V$. dahliae, with variable efficiencies [5-7]. ATMT is widely used for transforming various materials such as protoplasts, spores or hyphae of several fungal species $[8,9]$. In $V$. dahliae, ATMT has 
been used for targeted gene disruption [7, 10-13] or deletion [14-16], but it is laborious and time-consuming. PEG-mediated transformation of $V$. dahliae was first reported in 1995 and has yielded a high efficiency of transformation [17-19]; however, obtaining the large amounts of high-quality protoplasts crucial to the success of the method is difficult for many fungal species including $V$. dahliae. Moreover PEG-mediated transformation results in a high percentage of transient transformation. Yet for filamentous fungi, this method has been ideal because it is simple and fast [20].

RNA interference (RNAi) is an effective tool to investigate gene function in various organisms [21-24]. In filamentous fungi, plasmid constructs expressing dsRNA have been applied for this purpose with a silencing efficiency between 70-90 \% [25-28]. Although using this procedure for silencing gene is efficient, designing an RNAi plasmid is laborious. Synthetic siRNA can be used for the same purpose, e.g., incubation of synthetic siRNA with germinating spores of $A$. nidulans successfully silenced the target gene, leading to reduced mycelial growth [29]. In another study, synthetic dsRNA had in vitro antifungal activity against adenylate cyclase, DNA polymerase alpha subunit and DNA polymerase delta subunit in F. oxysporum and hindered spore germination [30]. However, transforming spores of certain fungal species like $V$. dahliae with siRNA is difficult as we have tried different ways to transform but obtained no satisfactory results (unpublished data). Thus, methods to directly transform protoplasts with synthetic siRNA to elucidate gene function have been sought. As reported for Fusarium sp. HKF15, siRNAs designed against hydroxymethyl glutaryl coenzyme A reductase $(h m g R)$ and farnesyl pyrophosphate synthase (fpps) were used to transform protoplasts and knockdown these genes, however the silencing was effective for only $48 \mathrm{~h}$ [31].

Our main objective was to develop an easy and quick method to transform $V$. dahliae and facilitate screening of essential genes. First, we developed a protocol using one enzyme to obtain high quality protoplasts from $V$. dahliae with excellent regeneration efficiency in TB3 broth. We then compared variations in PEG-mediated transformation and electroporation methods to develop the most efficient protocol to transform the protoplasts with the GFP plasmid (circular and linear). We also used synthetic siRNAs (19-nt duplex with 2-nt 3' overhangs) targeting the GFP gene in the GFP-transformed strain (Vd-GFP) and the Vta2 gene, a regulatory gene that is essential for growth and conidiation of $V$. dahliae [16], in the wild-type strain (Vd-wt) using PEG-mediated transformation to test whether the siRNAs can enter the protoplasts and inhibit the expression of these genes. Our results indicated that PEG-mediated transformation is more effective than electroporation. Moreover the transformation efficiency for siRNAs and the linear GFP cassette was significantly higher than with the circular GFP plasmid.

Our method of protoplast isolation, regeneration and transformation has advantages over other available methods in its rapidity and ease for generating protoplasts using a single enzyme and transforming the protoplasts with high efficiency. These techniques are conducive for the study of gene function using siRNA silencing or gene deletion in a short period of time.

\section{Methods}

\section{Fungal growth and spore harvesting}

Strain V991 of $V$. dahliae, a highly toxic and defoliating wild-type pathogenic strain, provided by Prof. Guiliang Jian of the Institute of Plant Protection, Chinese Academy of Agricultural Sciences (CAAS), was cultured on PDA plates at $25{ }^{\circ} \mathrm{C}$ for 7-10 days. Sterile distilled water was added to the plates to harvest spores by gently scraping the agar with a sterile loop. The resulting suspension was filtered through a sterile $40 \mu \mathrm{m}$ nylon filter (Falcon, REF352340) and centrifuged at $4000 \mathrm{rpm}$ for $5 \mathrm{~min}$. The final spore concentration was adjusted to $1.5 \times 10^{7} / \mathrm{mL}$.

\section{Protoplast isolation}

Driselase (Sigma D-9515), selected after comparing with a variety of enzymes (cellulase: Sigma C1184; snailase: BBI SB0870; lysozyme: Sigma 62970), was prepared by dissolving $500 \mathrm{mg}$ driselase in $25 \mathrm{ml} \mathrm{NaCl}(0.7 \mathrm{M})$ and centrifuged at $12,000 \mathrm{rpm}$ for $10 \mathrm{~min}$. The supernatant was taken and purified using $0.22 \mu \mathrm{m}$ filters (MILLEX ${ }^{\circ} \mathrm{GP}$ ). Two milliliters of $V$. dahliae spores $\left(1.5 \times 10^{7} / \mathrm{ml}\right)$ were cultured in $100 \mathrm{~mL}$ Complete Medium (CM: yeast extract $6 \mathrm{~g}$, casein acid hydrolysate $6 \mathrm{~g}$ and $10 \mathrm{~g}$ sucrose in $1 \mathrm{~L}$ $\mathrm{H}_{2} 0$ ) for $16-24 \mathrm{~h}$ at $28^{\circ} \mathrm{C}$ and $150 \mathrm{rpm}$. Mycelia were then separated from the culture and medium using a sterile $40 \mu \mathrm{m}$ nylon filter, then washed $2-3$ times with $0.7 \mathrm{M} \mathrm{NaCl}$. The harvested mycelia were aseptically transferred to $10 \mathrm{ml}$ of the driselase solution and incubated at $33{ }^{\circ} \mathrm{C}$ for $0.5-3.5 \mathrm{~h}$ at $60 \mathrm{rpm}$. The preparation was then checked every $30 \mathrm{~min}$ for protoplast release. After the incubation time, the mixture was then filtered using a sterile $40 \mu \mathrm{m}$ nylon filter to remove any hyphal fragments, and the protoplasts were centrifuged at $2800 \mathrm{rpm}$ for $5 \mathrm{~min}$. The supernatant was discarded, and the pellet was washed $2-3$ times either with $1 \mathrm{M}$ sorbitol, in case the protoplast has to be used for electroporation, or with STC buffer $(20 \%$

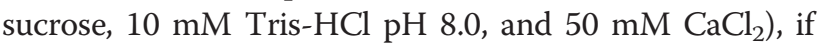
used for PEG-mediated transformation. The concentration of protoplasts was adjusted with either $1 \mathrm{M}$ sorbitol or STC to $10^{6} / \mathrm{ml}$. 


\section{Regeneration of protoplasts}

The ability of the protoplasts to regenerate was examined in CM, TB3 and Czapek-Dox broths. Briefly, $200 \mu \mathrm{l}$ protoplasts $\left(10^{6} / \mathrm{ml}\right)$ were cultured in $5 \mathrm{ml}$ broth and incubated at $25{ }^{\circ} \mathrm{C}$ for $18 \mathrm{~h}$. Protoplasts were observed for regeneration with a light microscope at $20 \times$ magnification, and the percentage of regeneration was calculated by counting the number of regenerated protoplasts out of total protoplasts cultured. In order to isolate a single colony, the regenerated protoplast suspension was centrifuged at $2800 \mathrm{rpm}$, the supernatant discarded and pellet was resuspended in $200 \mu \mathrm{l} \mathrm{CM}$ broth, serially diluted and cultured on PDA for 5-7 days until the colonies appeared.

\section{GFP plasmid and siRNAs}

The GFP plasmid (pCH-sGFP, Additional file 1) was kindly provided by Professor Xie Bingyan of the Institute of Vegetables and Flowers, CAAS. Primers GFP-1 5' CTTTCGACACTGAAATACGTCG3' and GFP-2 5' GCATCAGAGCAGATTGTACTGAGAG3' were used to amplify the GFP cassette from the GFP plasmid.

The siRNAs targeting different regions of the GFP gene (siRNA-gfp1, siRNA-gfp2, siRNA-gfp3 and siRNAgfp4) and the Vta2 gene (siRNA-vtaNC, siRNA-vta1, siRNA-vta2, siRNA-vta3 and siRNA-vta4) were designed and synthesized by Oligobio, Beijing, China. The sequences of siRNAs are given in Table 1 and the positions of these siRNAs along the genes are shown in Additional file 1 and Additional file 2.

\section{PEG-mediated transformation}

For PEG-mediated transformation, an established protocol was followed with some modifications [32]. Briefly, $200 \mu \mathrm{l}$ protoplasts $\left(10^{6} / \mathrm{ml}\right)$ was mixed with $12 \mu \mathrm{g}$ GFP plasmid (12.2 kb, bearing the hygromycin resistance cassette (hph) as a selection marker) or linear GFP cassette $(3.3 \mathrm{~kb})$ in a $50 \mathrm{ml}$ Falcon tube and incubated on ice for $30 \mathrm{~min} ; 1.5 \mathrm{ml} 60$ \% PEG solution in STC buffer was added to the tube dropwise, gently swirled and left at room temperature for $15 \mathrm{~min}$ followed by the addition

Table 1 siRNA sequences developed against GFP and Vta2

\begin{tabular}{lll}
\hline Name & Sense sequence & Antisense sequence \\
\hline siRNA-gfp1 & UCUUCAAGGACGACGGCAATT & UUGCCGUCGUCCUUGAAGATT \\
siRNA-gfp2 & GCCACAACGUCUAUAUCAUTT & AUGAUAUAGACGUUGUGGCTT \\
siRNA-gfp3 & GCAUGGACGAGCUGUACAATT & UUGUACAGCUCGUCCAUGCTT \\
siRNA-gfp4 & UCAAGGAGGACGGCAACAUTT & AUGUUGCCGUCCUCCUUGATT \\
siRNA-vta1 & CCAGGGCAUGUACUCUCAATT & UUGAGAGUACAUGCCCUGGT \\
siRNA-vta2 & GCAUGUACUCUCAACACAATT & UUGUGUUGAGAGUACAUGCTT \\
siRNA-vta3 & CCACGCUCAACACCUCUAUTT & AUAGAGGUGUUGAGCGUGGTT \\
siRNA-vta4 & GGCGCAACAAGCAAGCAAUTT & AUUGCUUGCUUGUUGCGCCTT \\
siRNA-vtaNC & UUCUCCGAACGUGUCACGUTT & ACGUGACACGUUCGGAGAATT \\
\hline
\end{tabular}

of $5 \mathrm{ml} \mathrm{TB} 3$ broth. The tubes were incubated at $25{ }^{\circ} \mathrm{C}$ for $18 \mathrm{~h}$, and GFP expression was checked with a fluorescence microscope (Zeiss Axio Imager M1, Jena, Germany). Transformants, transformed with GFP plasmid, were selected on PDA media supplemented with hygromycin B $(50 \mathrm{mg} / \mathrm{mL}$ final concentration) after regeneration in TB3 broth. Further confirmation of the positive transformants was made by PCR using GFP-CF 5'AGCTGGACGGCGACGTAAAC3' and GFP-CR 5' GATGGGGGTGTTCTGCTGGT3' primers.

\section{Electroporation}

Before using electroporation for transformation, protoplasts were shocked at different field strengths from 100$1000 \mathrm{~V} / \mathrm{cm}$ to ensure that electroporation had no or a very low lethal effect on the regeneration of protoplasts.

The protoplasts were mixed with $12 \mu \mathrm{g}$ of the GFP plasmid or linear GFP cassette as described above, using $1 \mathrm{M}$ sorbitol as the buffer, and kept on ice for $10 \mathrm{~min}$. The mixtures were transferred to a $0.2-\mathrm{cm}$ gap cuvette (BioRad, Hercules, CA), and different voltages (300, 400 and $500 \mathrm{~V}$ ) were applied for $5 \mathrm{~ms}$ using a GenPulser Xcell electroporation system (BioRad). Immediately after electroporation, the protoplasts were transferred to $5 \mathrm{ml}$ TB3 broth and incubated at $25{ }^{\circ} \mathrm{C}$ for $18 \mathrm{~h}$. After regeneration of protoplasts, the culture was centrifuged at $2800 \mathrm{rpm}$ for $5 \mathrm{~min}$. The supernatant was discarded, and the pellet was resuspended in $200 \mu \mathrm{l}$ TB3 and observed with a fluorescence microscope.

\section{siRNA inhibition assay for GFP and Vta2 genes}

For targeting the GFP gene, $200 \mu \mathrm{l}$ Vd-GFP protoplasts $\left(10^{6} / \mathrm{ml}\right)$ were transformed with $10 \mu \mathrm{M}$ siRNA-gfp1, siRNA-gfp2, siRNA-gfp3 or siRNA-gfp4 by PEGmediated transformation and regenerated for $18 \mathrm{~h}$ as described. Inhibition of GFP expression was checked using fluorescence microscopy by counting the number of hyphae with fluorescence. The percentage of GFP inhibition was determined by dividing the number of hyphae with no fluorescence on the number of hyphae with fluorescence multiplied by 100 .

Similarly, for silencing Vta2 gene, protoplasts obtained from Vd-wt were treated with siRNA-vta1, siRNA-vta2, siRNA-vta3 and siRNA-vta4 independently in a final concentration of $10 \mu \mathrm{M}$ or with $2.5 \mu \mathrm{M}$ siRNAs mix using PEG-mediated transformation in RNase free environment. siRNA-vtaNC was used as a negative control. Briefly, protoplasts obtained from vd-wt $\left(10^{6} / \mathrm{ml}\right)$ were mixed with either of the siRNAs or with mixed siRNAs in $50 \mathrm{~mL}$ falcon tube and incubated on ice for $30 \mathrm{~min}$; $1.5 \mathrm{ml} 60$ \% PEG solution in STC buffer was added to the tube dropwise, gently swirled and left at room temperature for $15 \mathrm{~min}$ followed by the addition of $5 \mathrm{ml}$ TB3 broth. After $18 \mathrm{~h}$ of incubation in TB3 broth, the 
cultures were centrifuged at $2500 \mathrm{rpm}$ for $5 \mathrm{~min}$, the supernatant was discarded, and the pellet was resuspended in $200 \mu \mathrm{l}$ TB3 broth and pipeted onto the center of CM agar plates. The colony diameter was measured after 10 days at $25^{\circ} \mathrm{C}$.

\section{qRT-PCR analysis of Vta2 expression level}

In order to further confirm that the reduction in growth of $V$. dahliae was due to silencing of Vta2 gene, we conducted qRT-PCR. After treating the protoplasts with siRNAs (siRNA-vtaNC, siRNA-vta1, siRNA-vta2, siRNAvta3, siRNA-vta4 and siRNA-vtamix respectively), they were cultured in TB3 broth for $72 \mathrm{~h}$ and the mycelia were harvested for RNA extraction by RNA Extraction Kit (YPHBio, Tianjin, China). qRT-PCR was carried out in 7500 Real Time PCR System (ABI, Massachusetts, USA). Gene specific primers were used: vta2-F 5'GGCTTC CTCAAGGTCGGCTATG3', vta2-R 5'GCTGCATGTCA TCCCACTTCTTC3', Vdactin-F 5'GGCTTCCTCAAGG TCGGCTATG3' and Vdactin-R 5'GCTGCATGTCATC CCACTTCTTC3' Vdactin was used as a housekeeping gene [33]. The relative expression of the targeted gene was analyzed using the $2^{-\Delta \Delta \mathrm{Ct}}$ method. The standard curve met experimental requirements $\left(R^{2}>0.99, \mathrm{E}>95 \%\right)$ [34].

\section{Statistical analysis}

All experiments were done in three independent replicates. Means \pm standard deviation and significant differences were determined using Duncan's multiple range test and $t$-test with $p$-values $<0.05$ in SPSS 17.0 software (SPSS Inc., Chicago, IL, USA).

\section{Results}

\section{Isolation and regeneration efficiency of protoplasts}

In order to select an efficient enzyme for protoplasts isolation from $V$. dahliae, we treated the mycelia with different enzymes (driselase, cellulase, snailase and lysozyme) and found that driselase resulted in maximum protoplasts yield (Additional file 3). While investigating the effect of driselase concentration on the yield of protoplast, $20 \mathrm{mg} / \mathrm{mL}$ was found the best (Additional file 3).

For selecting the optimal mycelial age and enzymolytic time to isolate protoplasts, spores were cultured for different times $(16,18,20,22$ and $24 \mathrm{~h})$ and then treated with driselase $(0.5-3.5 \mathrm{~h})$. The optimal mycelial age was found to be $20 \mathrm{~h}$ which yielded $5.5 \times 10^{7} / \mathrm{ml} \pm 0.275$ protoplasts when treated with driselase (Fig. 1a), while $2.5 \mathrm{~h}$ enzymolysis time was observed to produce the maximum number of protoplasts for all culture ages (Fig. 1b). When the three media were tested for regeneration efficiency, the efficiency was highest in TB3 (65 \pm 3 \%) (Fig. 1c).

\section{Observation of fluorescence from GFP expression}

Soon after PEG-mediated transformation and electroporation, the protoplasts were cultured for $18 \mathrm{~h}$ in TB3 broth to detect GFP expression as an indicator of transformation. Strong GFP fluorescence was observed in the transformed protoplasts, but none was seen in the $\mathrm{Vd}$ wt (Fig. 2a). PEG-4000 gave the highest transformation of all the methods for both linear GFP $(600 \pm 20$ transformants/ $\mu \mathrm{g}$ DNA) and for GFP plasmid $(250 \pm 10$

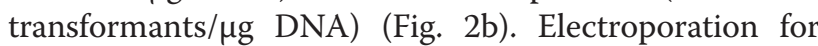
both GFP plasmid (24 \pm 1 transformants/ $\mu \mathrm{g}$ DNA) and linear GFP cassette ( $29 \pm 1$ transformants/ $\mu \mathrm{g}$ DNA) was significantly lower than the PEG-mediated (PEG-4000) transformation.

\section{GFP transformants selection and stability of the transgene}

GFP transformants derived from GFP plasmid transformation were selected after 5-7 days of culturing the regenerated protoplasts on PDA plates supplemented with hygromycin B. The selected GFP transformants fluoresced strongly when viewed with fluorescence microscopy. Further confirmation of the transformants was made by PCR (Additional file 4). Expression of GFP was observed from three generations of transformants, indicating stable GFP expression throughout these three generations.

\section{Silencing of GFP gene in strain Vd-GFP with siRNAs}

Protoplasts of strain Vd-GFP were treated with the different siRNAs targeting the GFP gene, and checked for inhibition of GFP expression after regeneration (Fig. 2c). We found out that siRNA-gfp4 gave the best silencing efficiency (up to $100 \%$ ) compared with $10 \%$ or less with siRNA-gfp1, siRNA-gfp2 and siRNA-gfp3 (Fig. 2d). The silencing of the GFP gene lasted for at least $72 \mathrm{~h}$.

\section{Silencing of Vta2 gene}

To validate whether $V$. dahliae genes can be silenced by siRNA using Vta2 as a reference gene, the gene was successfully silenced with siRNAs. On CM plates, the colony diameter of siRNA-vta1 group $(2.8 \mathrm{~cm})$ was significantly smaller than that of the siRNA-vtaNC group $(4.6 \mathrm{~cm})$ (Fig. 3a and b). The colony diameters of siRNA-vta2, siRNA-vta3, siRNA-vta4 and siRNA-vtamix groups were $3.6 \mathrm{~cm}, 3.5 \mathrm{~cm}, 3.2 \mathrm{~cm}$ and $3.0 \mathrm{~cm}$, respectively. As determined by colony diameter, siRNA-vta1 had the best silencing efficiency. To further confirm whether the reduction in colony diameter was due to silencing of Vta2 gene, qRT-PCR was conducted to determine the relative expression level of this gene in all the groups. The data was in accordance with that obtained from colony assessment. Expression level of 

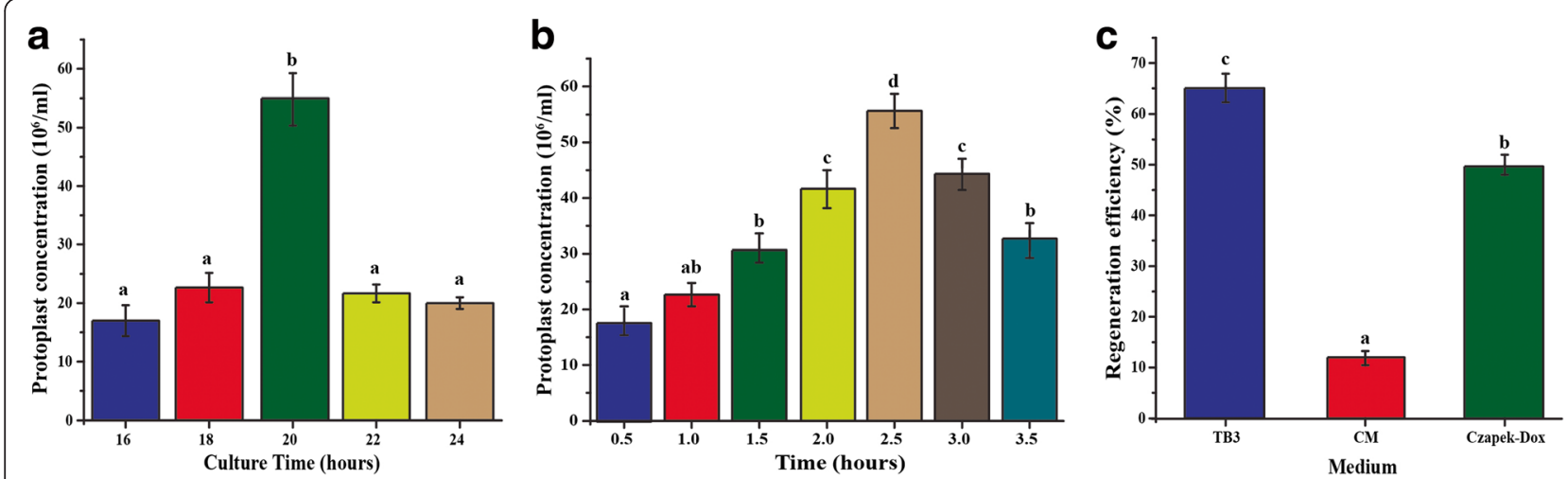

Fig. 1 Optimization of protoplast isolation and regeneration. a Protoplast isolation efficiency from mycelia cultured for 16 to $24 \mathrm{~h}$ and then treated for $2.5 \mathrm{~h}$ in $10 \mathrm{ml}$ driselase mixture. b Protoplast isolation efficiency after various digestion times with driselase. Mycelia were harvested at $20 \mathrm{~h}$ post inoculation. c Regeneration efficiency in different media. Protoplasts (200 $\mu \mathrm{l} \mathrm{of} \mathrm{10 \% /ml)} \mathrm{were} \mathrm{cultured} \mathrm{in} 5 \mathrm{ml}$ TB3, CM or Czapek-Dox broth. After $18 \mathrm{~h}$, the regeneration efficiency was measured as the number of protoplast regenerated out of total number of protoplast cultured multiplied by 100

Vta2 in siRNA-vta1 group was significantly lower than the other groups (Fig. 3c).

\section{Discussion}

In this study, we isolated and regenerated protoplasts from $V$. dahliae, then transformed the protoplasts with the GFP plasmid and linear GFP cassette using PEG-mediated transformation and electroporation, and silenced the GFP and Vta2 genes using siRNAs.

Protoplasts have been isolated from many fungal species at various efficiencies depending on the species and conditions. Driselase has proved efficient for protoplast isolation from Fusarium graminearum (ca $10^{9} \mathrm{~g}^{-1}$ wet mass) and Ascosphaera apis $\left(98.36 \times 10^{5} \mathrm{~mL}^{-1}\right.$ of protoplasts) $[35,36]$. For $V$. dahliae, protoplasts were previously isolated using a combination of two enzymes [18, 19]. In our study, we isolated protoplasts from $V$. dahliae by using a single enzyme driselase, with up to $90 \%$ efficiency. The main differences in our protocol and that developed in the previous study [19] are the number of spores they cultured for protoplasts isolation and the enzymolysis temperature. In our study $1.5 \times 10^{7} / \mathrm{ml}$ spores were cultured for obtaining mycelia to be digested with the enzyme while they used $10^{6} / \mathrm{ml}$. We used $33{ }^{\circ} \mathrm{C}$ as the optimum enzymolysis temperature and $20 \mathrm{~h}$ old culture the best for protoplast isolations as compared to their $30{ }^{\circ} \mathrm{C}$ and $24 \mathrm{~h}$ old culture. There is a difference in the media used for the growth of mycelia as well between the two protocols that can also have a significant effect on the protoplast production [36-39].

The efficiency of protoplast isolation, in addition to the digestion enzyme and other factors, also depends on the age of the mycelia. Young and exponentially growing mycelia are the best choices for protoplast isolation [36], but the optimal age of the mycelia varies for different species, e.g., $60 \mathrm{~h}$ for Blakeslea trispora and 2 days for
Pleurotus pulmonarius and Pleurotus florida [40, 41]. For $V$. dahliae, previous studies have used 24-h-old mycelia for protoplast isolation $[18,19]$, but here we obtained more protoplasts from the 20-h culture than from the 24-h culture. The probable reason for this can be the sensitivity of the younger mycelia to the digesting enzymes, with the increase in growth the cell wall becomes thicker and the mycelia would be digested more difficultly leading to decreased protoplast yield $[36,38,39]$. In addition to the age of mycelia, the protoplast yield also depends on the duration of the enzyme digestion, which has ranged from $3 \mathrm{~h}$ to $16 \mathrm{~h}$ for maximum protoplast release in other fungal species [37, 40, 42]. The optimum time of enzymolysis in our study was $2.5 \mathrm{~h}$. Less time is presumably not enough for all the mycelia to be digested by the enzyme, while prolonged enzymolyis can result in the breaking of protoplasts [37, 40-42].

Regeneration of protoplasts is a vital step and is the main limiting factor in a transformation experiment. Thus, a high frequency of regeneration is necessary for genetic manipulation of the particular fungus. Protoplasts from different fungi have been isolated with various regeneration frequencies, ranging from 3.3 to $77.5 \%$ [37, 40-42], partly depending on the media used to culture the protoplast. For example, the protoplast regeneration efficiencies for B. trispora and Nodulisporium sylviforme were found to be $77.5 \%$ and $72 \%$ on PDA respectively while the regeneration frequencies decreased (for B. trispora $32.5 \%$ on RM and for N. sylviforme $44 \%$ on CM) with the use of other media [40, 42]. In our study, the frequency of regeneration was about 5-fold higher in TB3 broth than in CM broth.

To increase the transformation efficiency of $V$. dahliae protoplasts, we also tested a number of protocols to determine the best one. Transformation efficiency of 

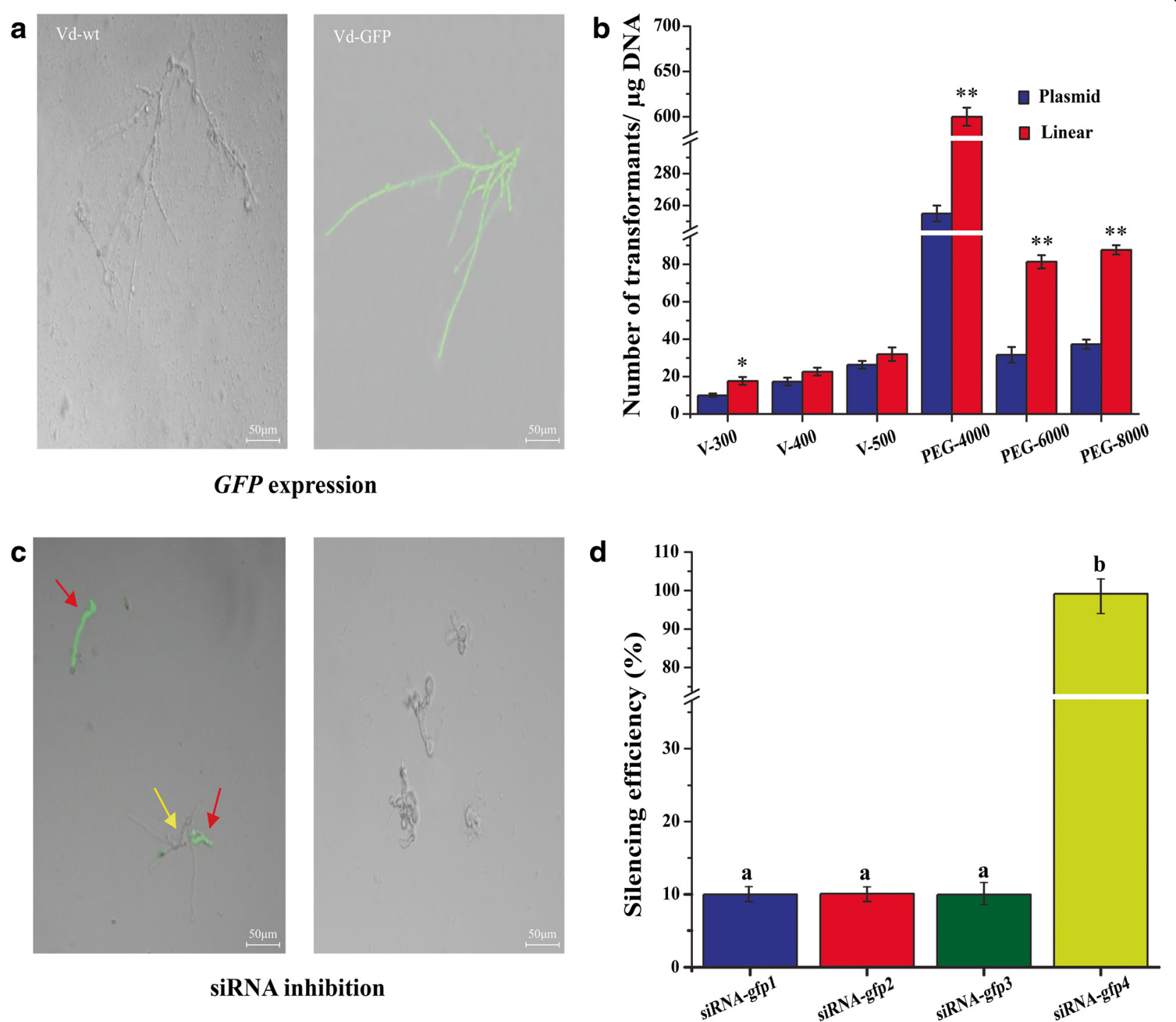

Fig. 2 Fluorescence detection of GFP expression in hyphae regenerated from transformed protoplast of $V$. dahliae. a GFP expression after $18 \mathrm{~h}$ of incubation. Protoplasts $\left(200 \mu \mathrm{l}\right.$ of $\left.1 \times 10^{6} / \mathrm{ml}\right)$ were transformed with $12 \mu \mathrm{g}$ of either GFP plasmid or linear GFP cassette and cultured. Fluorescence was observed in hyphae regenerated from transformed protoplast of $\mathrm{V}$. dahliae after $18 \mathrm{~h}$ incubation in TB3. $\mathbf{b}$ Transformation efficiency of protoplasts using electroporation (300-500 V) or PEG-mediated transformation (PEG-4000, 6000 and 8000). After transformation, the protoplasts were cultured in TB3 broth for $18 \mathrm{~h}$. Number of transformants was calculated per microgram DNA by counting the number of hyphae with GFP fluorescence. $\mathbf{c}$ Silencing of GFP expression with siRNA. Vd-GFP protoplasts were transformed with $10 \mu \mathrm{M}$ of 4 different siRNAs (siRNA-gfp1, siRNAgfp2, siRNA-gfp3 and siRNA-gfp4) separately by PEG-mediated transformation. The regenerated mycelia from the transformed protoplasts were observed for GFP fluorescence. d Assay for siRNA inhibition of GFP. Inhibition of GFP expression by siRNA-gfp1, siRNA-gfp2, siRNAgfp3 and siRNA-gfp4 was compared after in the regenerated hyphae from the transformed protoplasts

various fungal species with PEG has been variable, e.g., 102 transformants/1 $\mu$ g DNA for $V$. fungicola, 100-200 for the basidiomycete Pleurotus ostreatus [5, 43], and for $V$. dahliae, 10-50 transformants/1 $\mu \mathrm{g}$ DNA [18]. We obtained much higher yields in our experiments: 250 transformants/1 $\mu \mathrm{g}$ DNA using the GFP plasmid $(12.2 \mathrm{~kb})$ and 600 using the linear GFP cassette $(3.3 \mathrm{~kb})$ and PEG4000. The higher frequency of transformation might be due to the high quality of protoplasts obtained. Plasmid size also plays a vital role in the transformation efficiency. Previous studies have indicated that increasing plasmid size results in decreased transformation efficiency [44, 45]. The fewer transformants obtained with the GFP plasmid in comparison to the linear GFP cassette is thus probably due to the large size of the plasmid. On the other hand, transforming $V$. dahliae protoplast using electroporation did not yield promising results for either of the GFP plasmids. The main hurdle in electroporation is the regeneration of the protoplasts. As the voltage increases, the regeneration capacity of the 


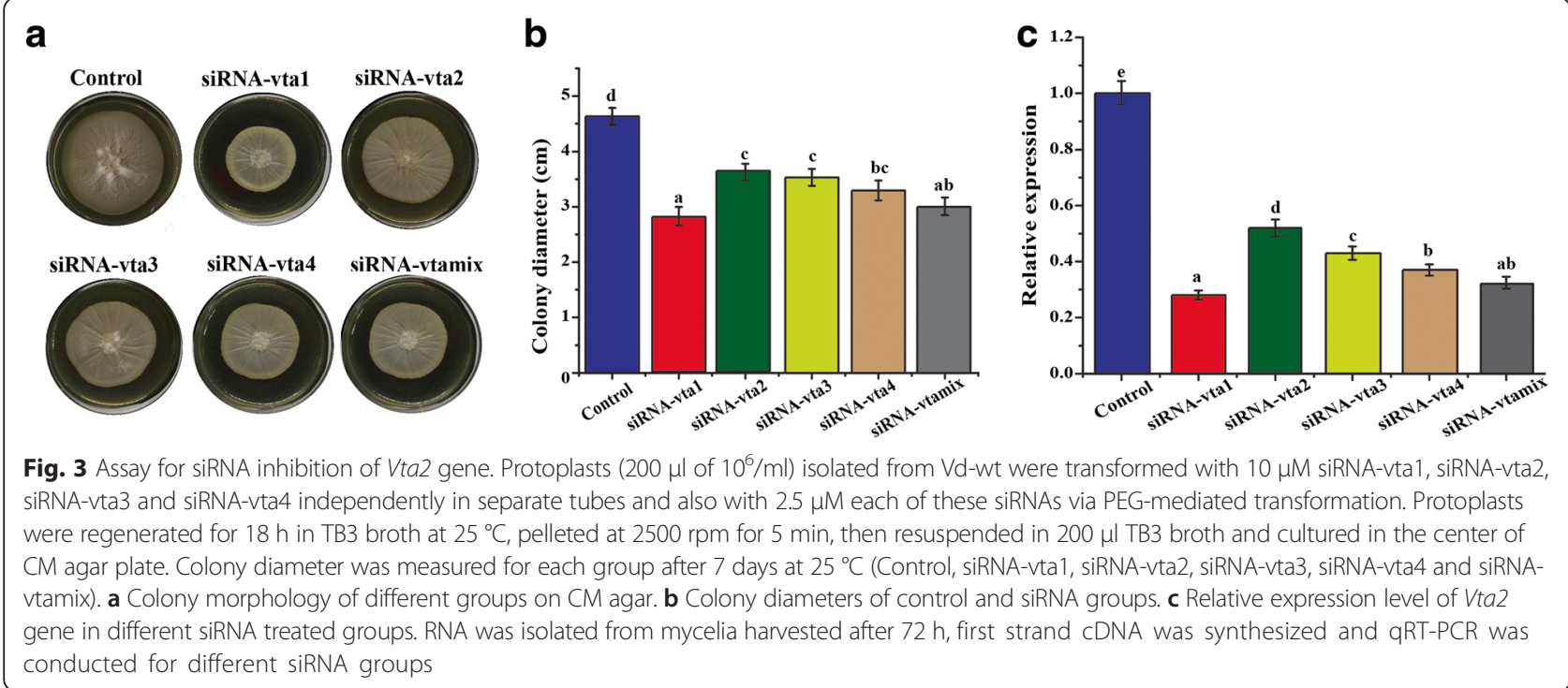

protoplast decreases. At low voltage (300-500 V), the transformation efficiency ranged from 10 to 29 transformants/1 $\mu \mathrm{g}$ DNA for GFP plasmid and linear GFP cassette, respectively, much lower than with PEG4000.

RNAi is a powerful reverse genetics tool for deciphering gene function in various organisms including fungi [46]. Characterizing gene function using gene deletion, disruption or insertion is a time-consuming process. Downregulation of a gene using RNAi is an alternative method in functional genomics as it is a rapid process as compared to the deletion or disruption of a gene. Moreover this approach is particularly helpful in studying essential genes or genes present in multiple copies within the genome that could compensate for each other's function. In fungi, synthetic siRNAs have been used to downregulate specific genes. For example, $h m g R$ and fpps in Fusarium sp. HKF15 were silenced by delivering siRNAs designed against these genes into the protoplasts [31]. In another study, three siRNA sequences (Nor-Ia, Nor-Ib, Nor-Ic) targeting the mRNA sequence of the aflD gene were tested for controlling aflatoxin production in Aspergillus flavus and Aspergillus parasiticus [47]. Designing siRNAs that are more effective at downregulating is essential for gene silencing. Several siRNAs designed from different sites within the same gene can have striking differences in silencing efficiency $[48,49]$ as shown by the silencing of the GFP gene at various efficiencies using different siRNAs.

$V t a 2$ gene was used as a reference gene for siRNA inhibition assay because its inhibition can easily be assessed from the colony growth [16]. After treating protoplasts obtained from Vd-wt transformed with different siRNAs designed for this gene, we observed a significant decrease in the colony diameter of the siRNA-treated groups compared with the control group. Differences in colony diameter were also observed among the siRNA groups, indicating that siRNA designed from different locations within the gene can have strikingly different silencing effects. The difference in the colony diameter among the siRNA groups and the control groups lasted for about 10 days, sufficient time for characterizing a gene.

\section{Conclusion}

Our improved method greatly increased the number of transformants per microgram of DNA over the others available. This method will be useful for elucidating gene functions by downregulating a particular gene of interest using siRNA and constructing gene deletion mutants of $V$. dahliae in a shorter time than required for ATMT.

\section{Additional files}

Additional file 1: Sketch of pCH-sGFP and position of siRNA along the GFP gene. (A) Diagram of GFP plasmid ( $\mathrm{pCH}$-sGFP). (B) Position of siRNAs along the GFP gene. siRNAs were designed and synthesized by Oligobio, Beijing, China. (JPG 9062 kb)

Additional file 2: Position of siRNAs along the $V t a 2$ gene of $V$. dahliae. The position of different siRNAs designed to target this gene is shown in this figure. Sequence underlined with different colors shows different siRNAs. (JPG 7797 kb)

Additional file 3: Selection of efficient enzyme and the effect of driselase concentration on the protoplasts isolation from $V$. dahliae. (A) Protoplasts isolation efficiency from the mycelia of Verticillium dahliae by treating with different enzymes, (B) The effect of driselase concentration on the release of protoplasts. (JPG $433 \mathrm{~kb}$ )

Additional file 4: Confirmation of GFP transformants by PCR. Single colony was selected and cultured in CM for 5-7 days. Mycelia were harvested and genomic DNA was isolated. PCR was carried out with gene specific primers. (JPG 152 kb) 


\section{Abbreviations}

ATMT, Agrobacterium tumefaciens-mediated transformation; CM, complete medium; PDA, potato dextrose agar; PEG, polyethylene glycol; siRNA, short interfering RNA; Vta, Verticillium transcription activator of adhesion

\section{Acknowledgments}

The authors are thankful to Dr. ljaz Ali and Mr. Adil Khan for revising the manuscript.

\section{Funding}

This work was supported by a grant from National Nonprofit Industry Research (201503109).

\section{Availability of data and materials}

All the data supporting our findings is included within the manuscript and its Additional files.

\section{Authors' contributions}

$\mathrm{HC}$ and $\mathrm{HG}$ designed the study and advised on protocols. LR and XS carried out the experimental procedures. XQ helped with experimental procedures and manuscript preparation. The manuscript was read and approved by all the authors.

\section{Competing interests}

The authors declare that they have no competing interests.

\section{Consent for publication}

Not applicable.

\section{Ethics approval and consent to participate}

Not applicable.

Received: 21 March 2016 Accepted: 15 July 2016

Published online: 26 July 2016

\section{References}

1. Fradin EF, Thomma BPHJ. Physiology and molecular aspects of Verticillium wilt diseases caused by V. dahliae and V. albo-atrum. Mol Plant Pathol. 2006;7:71-86.

2. Klosterman SJ, Atallah ZK, Vallad GE, Subbarao KV. Diversity, pathogenicity, and management of Verticillium species. Annu Rev Phytopathol. 2009;47:39-62.

3. Pegg GF, Brady BL. Verticillium Wilts. CABI Pulishing: New York, NY, USA; 2002.

4. Dobrowolska A, Staczek P. Development of transformation system for Trichophyton rubrum by electroporation of germinated conidia. Curr Genet. 2009;55:537-42.

5. Amey RC, Athey-Pollard A, Burns C, Mills PR, Bailey AM, Foster GD. PEG-mediated and Agrobacterium-mediated transformation in the mycopathogen Verticillium fungicola. Mycol Res. 2002;106:4-11.

6. Mullins ED, Chen X, Romaine P, Raina R, Geiser DM, Kang S. AgrobacteriumMediated Transformation of Fusarium oxysporum: An Efficient Tool for Insertional Mutagenesis and Gene Transfer. Phytopathology. 2001;91:173-80.

7. Dobinson KF, Grant SJ, Kang S. Cloning and targeted disruption, via Agrobacterium tumefaciens -mediated transformation, of a trypsin protease gene from the vascular wilt fungus Verticillium dahliae. Curr Genet. 2004;45:104-10.

8. de Groot MJA, Bundock P, Hooykaas PJJ, Beijersbergen AGM. Agrobacterium tumefaciens-mediated transformation of filamentous fungi. Nat Biotechnol. 1998;16:839-42.

9. Chen X, Stone M, Schlagnhaufer C, Romaine CP. A Fruiting Body Tissue Method for Efficient Agrobacterium-Mediated Transformation of Agaricus bisporus. Appl Environ Microbiol. 2000;66:4510-3.

10. Tzima A, Paplomatas EJ, Rauyaree P, Kang S. Roles of the catalytic subunit of CAMP-dependent protein kinase A in virulence and development of the soilborne plant pathogen Verticillium dahliae. Fungal Genet Biol. 2010;47: 406-15.

11. Rauyaree P, Ospina-Giraldo MD, Kang S, Bhat RG, Subbarao KV, Grant SJ, et al. Mutations in VMK1, a mitogen-activated protein kinase gene, affect microsclerotia formation and pathogenicity in Verticillium dahliae. Curr Genet. 2005;48:109-16.
12. Klimes $\mathrm{A}$, Dobinson KF. A hydrophobin gene, $\mathrm{VDH}$, is involved in microsclerotial development and spore viability in the plant pathogen Verticillium dahliae. Fungal Genet Biol. 2006;43:283-94.

13. He X-J, Li X-L, Li Y-Z. Disruption of Cerevisin via Agrobacterium tumefaciens -mediated transformation affects microsclerotia formation and virulence of Verticillium dahliae. Plant Pathol. 2015;64:1157-67.

14. Hoppenau CE, Tran V-T, Kusch H, Aßhauer KP, Landesfeind M, Meinicke P, et al. Verticillium dahliae VdTHI4, involved in thiazole biosynthesis, stress response and DNA repair functions, is required for vascular disease induction in tomato. Environ Exp Bot. 2014;108:14-22.

15. Qi X, Su X, Guo H, Qi J, Cheng H. A ku70 null mutant improves gene targeting frequency in the fungal pathogen Verticillium dahliae. World J Microbiol Biotechnol. 2015;31:1889-97.

16. Tran VT, Braus-Stromeyer SA, Kusch H, Reusche M, Kaever A, Kuhn A, et al. Verticillium transcription activator of adhesion Vta2 suppresses microsclerotia formation and is required for systemic infection of plant roots. New Phytol. 2014;202:565-81.

17. Dobinson KF. Genetic transformation of the vascular wilt fungus Verticillium dahliae. Can J Bot. 1995;73:710-5.

18. Wang $Y$, Xiao $S$, Xiong $D$, Tian C. Genetic transformation, infection process and qPCR quantification of Verticillium dahliae on smoke-tree Cotinus coggygria. Australas Plant Pathol. 2012;42:33-41.

19. Xiao S, Sun Y, Tian C, Wang Y. Optimization of factors affecting protoplast preparation and transformation of smoke-tree wilt fungus Verticillium dahliae. African J Microbiol Res. 2013;7:2712-8.

20. Liu Z, Friesen TL. Polyethylene Glycol (PEG)-Mediated Transformation in Filamentous Fungal Pathogens. In: Bolton MD, Thomma BPHJ, editors. Plant Fungal Pathog. Methods Protoc. Methods Mol. Biol. Totowa, NJ: Humana Press; 2012. p. 365-75,

21. Fjose A, Ellingsen $\mathrm{S}$, Wargelius $\mathrm{A}$, Seo H-C. RNA interference: mechanisms and applications. Biotechnol Annu Rev. 2001;7:31-57.

22. Maeda I, Kohara Y, Yamamoto M, Sugimoto A. Large-scale analysis of gene function in Caenorhabditis elegans by high-throughput RNAi. Curr Biol. 2001; 11:171-6.

23. Clemens JC, Worby CA, Simonson-Leff N, Muda M, Maehama T, Hemmings BA, et al. Use of double-stranded RNA interference in Drosophila cell lines to dissect signal transduction pathways. Proc Natl Acad Sci. 2000;97:6499-503.

24. Malhotra P, Dasaradhi PVN, Kumar A, Mohmmed A, Agrawal N, Bhatnagar RK, et al. Double-stranded RNA-mediated gene silencing of cysteine proteases (falcipain-1 and -2) of Plasmodium falciparum. Mol Microbiol. 2002;45:1245-54.

25. Nakayashiki H, Hanada S, Quoc NB, Kadotani N, Tosa Y, Mayama S. RNA silencing as a tool for exploring gene function in ascomycete fungi. Fungal Genet Biol. 2005;42:275-83.

26. Singh S, Braus-Stromeyer SA, Timpner C, Tran VT, Lohaus G, Reusche M, et al. Silencing of Vlaro2 for chorismate synthase revealed that the phytopathogen Verticillium longisporum induces the cross-pathway control in the xylem. Appl Microbiol Biotechnol. 2010;85:1961-76.

27. Ullán RV, Godio RP, Teijeira F, Vaca I, García-Estrada C, Feltrer R, et al. RNA-silencing in Penicillium chrysogenum and Acremonium chrysogenum: validation studies using $\beta$-lactam genes expression. J Microbiol Methods. 2008; 75:209-18.

28. Shimizu T, Ito T, Kanematsu S. Functional analysis of a melanin biosynthetic gene using RNAi-mediated gene silencing in Rosellinia necatrix. Fungal Biol. 2014;118:413-21.

29. Khatri M, Rajam MV. Targeting polyamines of Aspergillus nidulans by siRNA specific to fungal ornithine decarboxylase gene. Med Mycol. 2007:45:211-20.

30. Mumbanza FM, Kiggundu A, Tusiime G, Tushemereirwe WK, Niblett C, Bailey A. In vitro antifungal activity of synthetic dsRNA molecules against two pathogens of banana, Fusarium oxysporum f. sp. cubense and Mycosphaerella fijiensis. Pest Manag Sci. 2013;69:1155-62.

31. Deshmukh R, Purohit HJ. siRNA mediated gene silencing in Fusarium sp. HKF15 for overproduction of bikaverin. Bioresour Technol. 2014;157:368-71.

32. Wang $Y$, Xiao $S$, Xiong D. Genetic transformation, infection process and qPCR quantification of Verticillium dahliae on smoke-tree Cotinus coggygria. Aust Plant Pathol. 2013;42:33-41.

33. Yang X, Ben S, Sun Y, Fan X, Tian C, Wang Y. Genome-Wide Identification, Phylogeny and Expression Profile of Vesicle Fusion Components in Verticillium dahliae. PLoS One. 2013;8, e68681.

34. Bustin SA, Benes V, Garson JA, Hellemans J, Huggett J, Kubista M, et al. The MIQE Guidelines: Minimum Information for Publication of Quantitative Real-Time PCR Experiments. Clin Chem. 2009;55:611-22. 
35. Marilyn GW, Michaela N, Laurie M, Margaret LB, Geoffrey DR, Peter JP, et al. Protoplast production and transformation of morphological mutants of the Quorn ${ }^{\oplus}$ myco-protein fungus, Fusarium graminearum $A 3 / 5$, using the hygromycin B resistance plasmid p AN7-1. Mycol Res. 1997;101:871-7.

36. Wubie AJ, Hu Y, Li W, Huang J, Guo Z, Xu S, et al. Factors Analysis in Protoplast Isolation and Regeneration from a Chalkbrood Fungus, Ascosphaera apis. Int J Agric Biol. 2014;16:89-96.

37. Dhar P, Kaur G. Optimization of different factors for efficient protoplast release from entomopathogenic fungus Metarhizium anisopliae. Ann Microbiol. 2009;59:183-6.

38. Shabana YM, Charudattan R. Preparation and Regeneration of Mycelial Protoplasts of Alternaria eichhorniae. J Phytopathol. 1997;145:335-8.

39. Li L, Yin Q, Liu X, Yang H. An efficient protoplast isolation and regeneration system in Coprinus comatus. African J Microbiol Res. 2010;4:459-65.

40. Li Y, Yuan Q, Du X. Protoplast from B-carotene-producing fungus Blakeslea trispora: Preparation, regeneration and validation. Korean J Chem Eng. 2008; 25:1416-21.

41. Eyini M, Rajkumar K, Balaji P. Isolation, Regeneration and PEG-Induced Fusion of Protoplasts of Pleurotus pulmonarius and Pleurotus florida. Mycobiology. 2006;34:73.

42. Zhao K, Zhou D, Ping W, Ge J. Study on the Preparation and Regeneration of Protoplast from Taxol-producing Fungus Nodulisporium sylviforme. Nat Sci. 2004;2:52-9.

43. Liu Y, Wang SX, Yin YG, Zhao S, Geng X, Xu F. Polyethylene glycol (PEG)-mediated transformation of the fused egfp-hph gene into Pleurotus ostreatus. African J Biotechnol. 2012;11:4345-53.

44. Vicky C, Lisa FD, Kerry AF, Sonja JL, Adrea AM. The effect of increasing plasmid size on transformation efficiency in Escherichia coli. J Exp Microbiol Immunol. 2002;2:207-23.

45. Ohse M, Takahashi K, Kadowaki Y, Kusaoke H. Effects of Plasmid DNA Sizes and Several Other Factors on Transformation of Bacillus subtilis ISW1214 with Plasmid DNA by Electroporation. Biosci Biotechnol Biochem. 1995;59: 1433-7.

46. Salame TM, Ziv C, Hadar Y, Yarden O. RNAi as a potential tool for biotechnological applications in fungi. Appl Microbiol Biotechnol. 2011; 89:501-12.

47. Abdel-Hadi A, Caley D, Carter D, Magan N. Control of Aflatoxin Production of Aspergillus flavus and Aspergillus parasiticus Using RNA Silencing Technology by Targeting aflD (nor-1) Gene. Toxins (Basel). 2011:3:647-59.

48. Holen T, Amarzguioui M, Wiiger MT, Babaie E, Prydz H. Positional effects of short interfering RNAs targeting the human coagulation trigger Tissue Factor. Nucleic Acids Res. 2002;30:1757-66.

49. Lam JK, Chow MY, Zhang Y, Leung SW. siRNA Versus miRNA as Therapeutics for Gene Silencing. Mol Ther Acids. 2015:4:e252.

\section{Submit your next manuscript to BioMed Central and we will help you at every step:}

- We accept pre-submission inquiries

- Our selector tool helps you to find the most relevant journal

- We provide round the clock customer support

- Convenient online submission

- Thorough peer review

- Inclusion in PubMed and all major indexing services

- Maximum visibility for your research

Submit your manuscript at www.biomedcentral.com/submit
Biomed Central 